\title{
Study of the Limit of the Technological Transition in the Field of Methanisation in Senegal (from Laboratory Scale to in-Situ Biodigester)
}

\author{
Jean Baptiste Mansaly ${ }^{1 *}$, Djicknoum Diouf ${ }^{1}$, Bruno Piriou ${ }^{2}$, \\ Diène Ndiaye ${ }^{1}$, Amadou Seydou Maïga ${ }^{1}$ \\ ${ }^{1}$ Laboratory of Electronics, Computer science, Telecommunications and Renewable Energy, Gaston Berger University, \\ Saint Louis, Senegal \\ ${ }^{2}$ Centre de coopération Internationale en Recherche Agronomique pour le Développement, Montpellier, France \\ Email: ^mansaly.jean-baptiste@ugb.edu.sn,djicknoum.diouf@ugb.edu.sn, \\ bruno.piriou@cirad.fr, amadou-seidou.maiga@ugb.edu.sn
}

How to cite this paper: Mansaly, J.B., Diouf, D., Piriou, B., Ndiaye, D. and Maïga, A.S. (2021) Study of the Limit of the Technological Transition in the Field of Methanisation in Senegal (from Laboratory Scale to in-Situ Biodigester). Journal of Sustainable Bioenergy Systems, 11, 215-226.

https://doi.org/10.4236/jsbs.2021.114014

Received: August 31, 2021

Accepted: October 18, 2021

Published: October 21, 2021

Copyright $\odot 2021$ by author(s) and Scientific Research Publishing Inc. This work is licensed under the Creative Commons Attribution International License (CC BY 4.0).

http://creativecommons.org/licenses/by/4.0/

\begin{abstract}
The Anaerobic digestion in Senegal is of particular interest to the scientific community given the availability of substrates and their distribution throughout the country. However, from a technological point of view, the existing installations seem to be obsolete, which does not allow to reproduce the results of the laboratory tests. Thus, the present study aims to take stock of the situation in relation to the studies carried out in laboratories and those concerning the actual monitoring of the bio-digesters in situ. In fact, most experimental bio-digesters operate under optimal implementation conditions with strict control of input and output parameters. However, this is not the case for reactors installed in the field, as these so-called bio-digesters are exposed to real environmental conditions with a periodic variation of the physic-chemical parameters in the reactors throughout the day. This leads to a differential behavior of the micro-organisms, thus affecting their performance. This results in lower yields for those digesters operating under real environmental conditions.
\end{abstract}

\section{Keywords}

Digestion Anaerobic, Substrate, Temperature, $\mathrm{pH}$, Inhibitory Factors

\section{Introduction}

The development of the methanization of organic waste and effluents is a major 
challenge for Senegal at several levels, notably the production of renewable energy and the preservation of soil quality through good management of the return of residual organic matter to the soil. The digestate resulting from the methanization process is therefore a new organic waste "product" intended for agricultural spreading. In fact, despite the advantages that the country has from the point of view of the availability of organic matter, the implementation of the process of anaerobic digestion in situ encounters some difficulties with respect to the experiments made at the level of laboratories. Thus since 1989, the Society for the Exploitation of Animal Resources in Senegal (SERAS) in collaboration with the Center for International Cooperation in Agronomic Research for Development (CIRAD) has decided to launch a pilot waste treatment operation at the slaughterhouse in Thiès, the second largest city in Senegal. The project, in the long term, consists of transferring the results obtained from Thiès to the Dakar slaughterhouse. In fact, 43,000 tons of waste are dumped annually in the bay of Hann, without prior treatment, not counting the water used to rinse the hides, which is loaded with toxic products as dangerous as arsenic [1]. This constitutes a major danger for the local populations, but also for those whose activities depend directly on it.

Furthermore, with Ministerial Order n ${ }^{\circ}$ 12,100 dated 30 December 2009 on the creation, organization and operation of the National Domestic Biogas Program of Senegal (PNB-SN). A national program called the National Domestic Biogas Program of Senegal (PNB-SN) is created, placed under the supervision of the Ministry in charge of Energy, through the Directorate of Hydrocarbons and Domestic Fuels (DHCD).

The program aims to create a sustainable biogas market for the benefit of Senegalese households. More specifically, the program aims to install at least 8000 biodigesters in the pilot zone covering the groundnut basin and the peri-urban area of Dakar, over the period 2009-2013.

- Establish an infrastructural framework for the permanent operation of biodigesters;

- Contribute to the livestock stalling policy;

- Provide cooking energy to rural households;

- Provide lighting for these households;

- To improve the farm by providing organic manure;

- To improve the conditions of women in rural areas;

- Reduce respiratory diseases due to smoke;

- Reduce the drain on woody reserves for cooking energy needs; etc.; and so on;

- Create hundreds of permanent and temporary jobs [2].

With this new situation, the scientific world is finding a major focus of interest by emphasizing research on an experimental (laboratory) scale in order to provide much more sustainable solutions. But the solutions thus proposed seem to be out of phase with the real environment of the digesters installed in-situ, hence the limit of technology transfer. This requires an inventory of the current 
situation for a better future for the biogas sector in Senegal.

\section{Material and Methods}

The methodology adopted for this study consists of first synthesizing the studies conducted in the laboratories and the results obtained in order to compare them with the results of daily monitoring of two types of biodigesters installed at the Assane Seck University in Ziguinchor for five (5) months.

\subsection{Case of Experimental Reactors}

Most experimental studies often meet pre-established standards to achieve desired results. For example, in anaerobic fermentation in the laboratory, the effluents and residues used are pre-treated beforehand as follows:

- Sampling (sorting)

- Conservation

- Grinding

All these practices aim to keep the physical-chemical and biochemical characteristics of the samples. And the type of substrate used in most methanization tests is: fermentable fractions of household waste (FFOM) and assimilated which are made up of kitchen waste, such as onion, potato, carrot, beet, salad, artichoke and food scraps (Figure 1).

Methanization tests are often carried out in well-dimensioned methanisers with control systems (Figure 2). This is not the case with in-situ biodigesters.

\subsection{Case of in-Situ Reactors}

This study was carried out in two types of biodigesters installed on the site of the Assane Seck University in Ziguinchor. These include a biodigester made of cement, which we will call BioC, and a second one made of fired clay, called BioA. The biodigesters studied are located at the extreme west end of the Assane Seck University, more precisely to the northwest of the amphitheater (AMPHI1). It is an isolated site from the rest of the buildings because, first and foremost, it is a
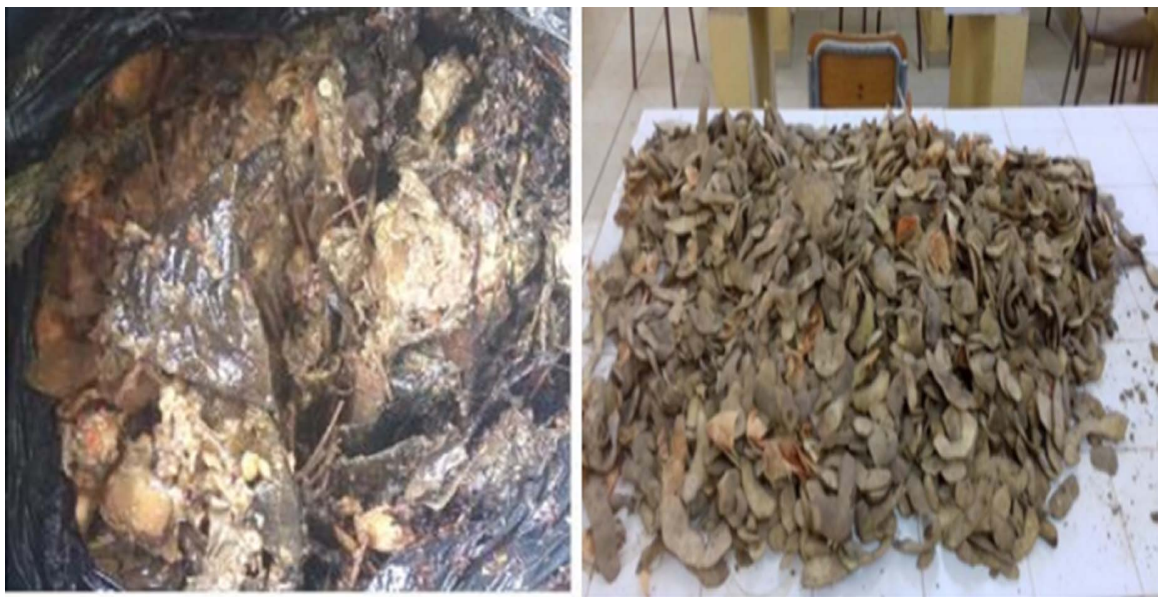

Figure 1. Fermentable fraction of household waste. 
biogas installation that presents ignition risks in the event of leaks. These precautions have been taken to avoid possible fire-related problems.

In addition, these biodigesters, like most of the installations in Senegal's national domestic biogas program (PNB-SN) are of the Chinese model (GGC 2047 amended PNB-SN) with a capacity of $10 \mathrm{~m}^{3}$ each (Figure 3). The aim of this work is to characterize the two types of substrates, cow dung (in BioC) and cow dung $85 \%+$ cashew apple $15 \%$ (in BioA), and to know how they behave in the two types of biodigesters. Loading was done according to the availability of the substrate, and sometimes the loading was done within an interval of two (02) or seven (07) days; to be able to adopt the habits of the users who use these types of digesters in the PNB-SN [4].

Pressed cashew apple was used because of its availability in this southern part of the country. However, this is due to the fact that after pressing, these residues

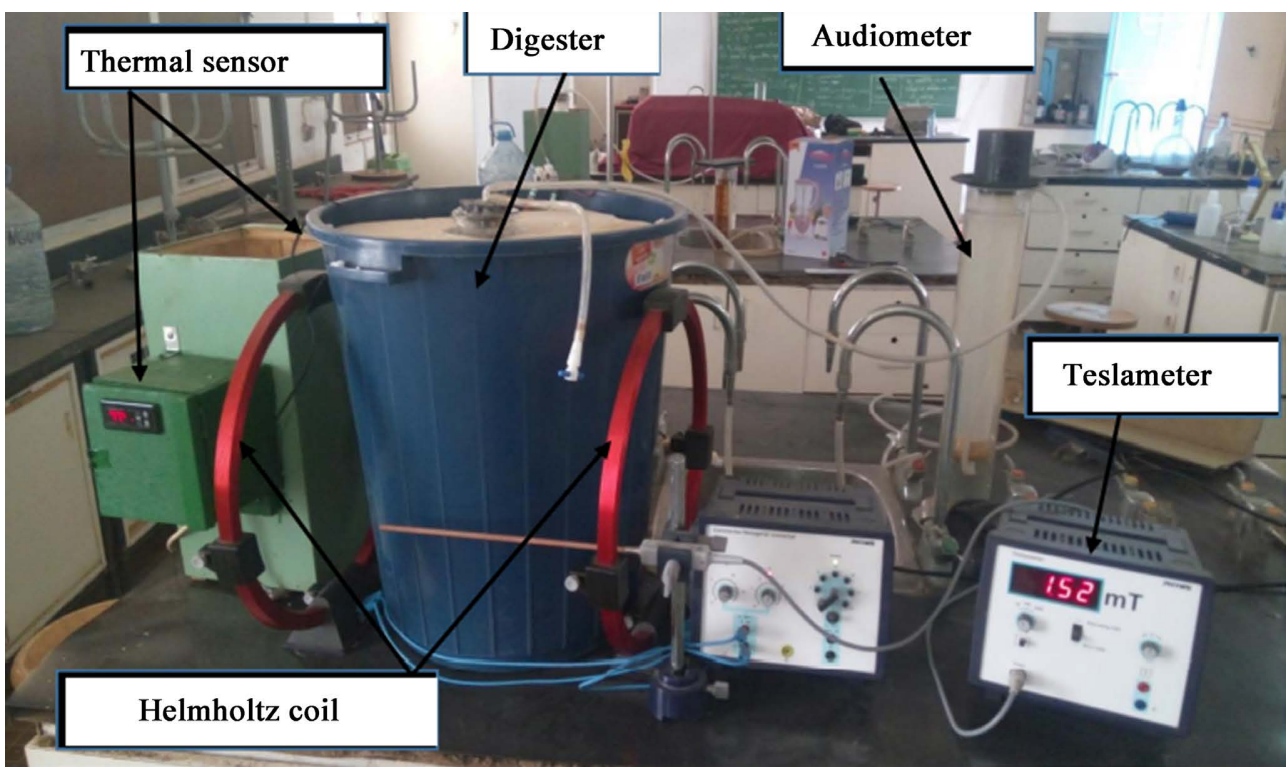

Figure 2. Biodigester with a temperature regulator and teslameter [3].

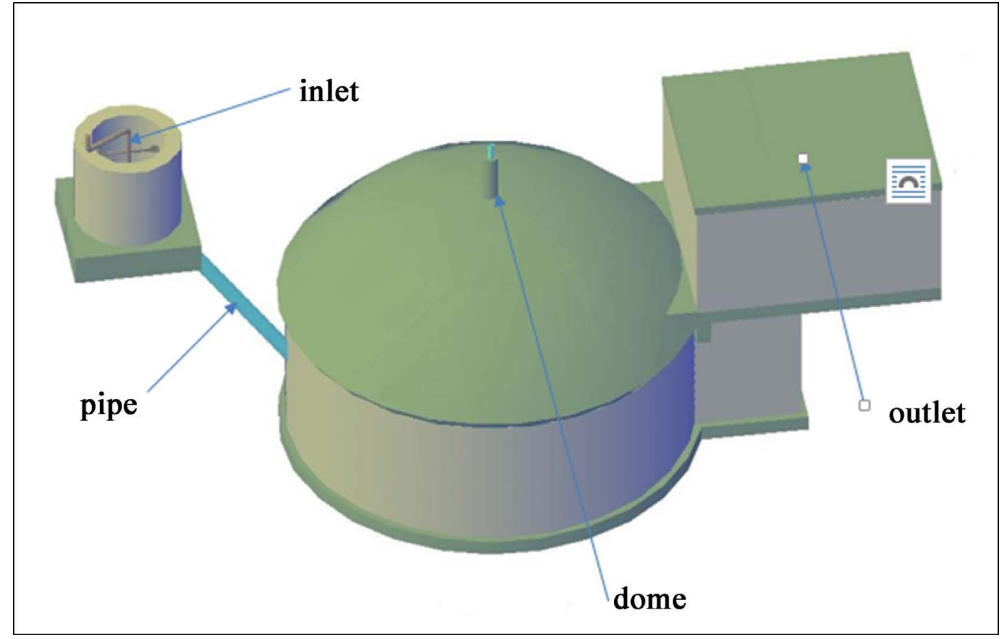

Figure 3. PUXIN digester model (PNB-SN) [4]. 
are directly on the ground with no final destination other than human pollution and nuisance. And the study consisted, among other things, of taking samples from the digestate in order to assess the $\mathrm{pH}$ of the environment. For other parameters such as temperature, gas chemistry and pressure, direct measurements were taken using measuring equipment. All the measurements were taken at the biogas site of the Assane Seck University in Ziguinchor. It is a place dedicated to biomass with biogas installations coupled with a unit for manufacturing bio coal from residues of organic origin (cashew nut shell, peanut shell, millet stalk). With the measurement results, a database was set up, the use of which enabled us to draw characteristic curves for the parameters studied.

\section{Results and Discussion}

The operation of a methanization process depends largely on two (2) parameters, namely temperature and $\mathrm{pH}$. These parameters must be monitored on a daily basis because they define the conditions of existence of the microbial flora. Indeed, a sudden change in temperature can cause a functional imbalance in the microbial population [5]. This is the case for the $\mathrm{pH}$ of the environment. A $\mathrm{pH}$ that is too acidic leads to a phenomenon called acidosis, whereas a basic $\mathrm{pH}$ simply leads to alkalosis. These two extreme phenomena cause the inhibition of anaerobic digestion processes because the $\mathrm{pH}$ of the medium must be neutral (between 6.5 and 8) [6]. Since our two digesters operate in mesophilic mode and do not have a control system, we had to take three (03) parameter readings per day:

- One catch in the morning (9 am)

- One catch at noon (12 h-1 h pm)

- One afternoon catch (3 - $4 \mathrm{pm})$

And this during the whole time of the follow-up, hence the following results.

\subsection{Units the Temperature of the Reaction Medium}

The temperature of these types of installations generally depends on the ambient temperature of the study area. This is why, in order to better evaluate the temperature of the methanisers, we looked at the monthly averages of the temperature of the environment and those of the digesters to see what correlation could exist, hence Table 1.

This table shows us a perfect correlation between the ambient temperature and those of the two systems, i.e. the temperatures increase in the same direction

Table 1. Relationship between digester temperature and ambient environment.

\begin{tabular}{cccccc}
\hline Month, & Jun & July & August & September & October \\
\hline AAT $\left({ }^{\circ} \mathrm{C}\right)$ & 27.8 & 26.8 & 26.7 & 28 & 31.6 \\
A BioC T $\left({ }^{\circ} \mathrm{C}\right)$ & 29.1 & 30.6 & 29.2 & 36.6 & 31.7 \\
A BioA T $\left({ }^{\circ} \mathrm{C}\right)$ & 30 & 29.9 & 29.3 & 36.2 & 32. \\
\hline
\end{tabular}


according to the months with values varying from:

- Average Ambient Temperature (AAT): $26.8^{\circ} \mathrm{C}$ to $31.6^{\circ} \mathrm{C}$

- Average BioC temperature: $29.1^{\circ} \mathrm{C}$ to $36.6^{\circ} \mathrm{C}$

- Average BioA temperature: $29.2^{\circ} \mathrm{C}$ to $36.2^{\circ} \mathrm{C}$

These behaviors from the point of view of the average temperature allowed us to understand the variation of the digester temperature as a function of the monitoring period with peaks observed at midday and the lowest temperatures recorded in the morning (Figure 4).

However, for digesters at the experimental scale, the temperature is fixed and regulated using specific equipment. For example, $35^{\circ} \mathrm{C}$ for mesophilic digestion. But also, and above all the possibility of evolving in a thermophilic regime $\left(45^{\circ} \mathrm{C}\right.$ $\pm 2^{\circ} \mathrm{C}$ ) which makes it possible to reduce the hydraulic retention time and accelerate the mechanization process [3] [7] and [8].

\subsection{The $\mathrm{pH}$ of the Reaction Medium}

The $\mathrm{pH}$ of our two digesters varies within the admitted ranges, with values ranging from 6.8 to 7.5 for BioA and from 7.2 to 7.7 for BioC as shown in Figure 5 [9]. The fact is that the $\mathrm{pH}$ in $\mathrm{BioC}$ is much more stable. And this could positively affect the pressure as well as the percentage composition of methane $\left(\mathrm{CH}_{4}\right)$ in the biogas composition of this digester. On the other hand, for laboratory or industrial scale digesters, $\mathrm{pH}$ variations are often corrected with the introduction of chemicals (soda in well-defined proportions) into the reactors [10]. This is not the case in our study because we want to have information on the actual behavior of the reactors in-situ.

\subsection{The Pressure of the Gas Produced by the Digesters}

As both digesters do not have gas meters or storage tanks, the biogas produced was quantified using a manometer. Once the valve was opened, the pressure
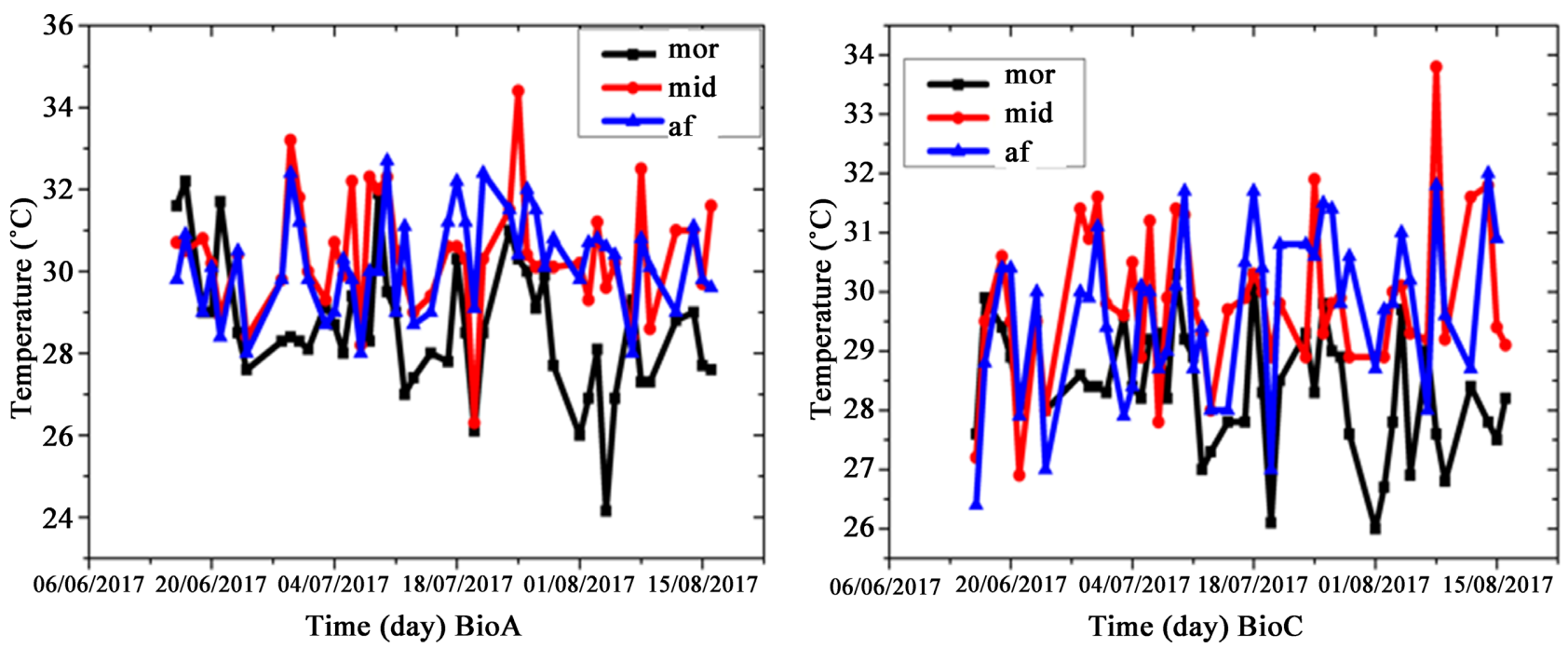

Figure 4. Temperature evolution in the two digesters as a function of time. 
displayed by the needle of the manometer could be read directly, which allowed us to follow the evolution of the pressure throughout the monitoring of our two systems (Figure 6). The pressure at the BioA level varies globally from 0.9 to 9.4 $\mathrm{kPa}$, with a slight variation during the setting hours. Most of the time, the pressure is lower than $6 \mathrm{kPa}$. On the other hand, for BioC, the pressure varies between 1.8 and $10.8 \mathrm{kPa}$ and is much more stable during the setting hours, with values often higher than $6 \mathrm{kPa}$. In fact, a $10 \mathrm{~m}^{3}$ digester in normal operation can reach a value of $12 \mathrm{kPa}$. But this value depends on the experimental conditions. In this case, the digesters are not loaded every day, because there is no daily supplier. Since the loading is not regular, it would be very difficult to speak in terms of the exact yield of gas produced.

Another phenomenon to be taken into consideration is that not all the gas produced is used and this could be the cause of sudden pressure drops in biodigesters. This is because the accumulation of gas in the dome could affect the bacterial population that is on the surface. Nevertheless, basic analysis of the gas

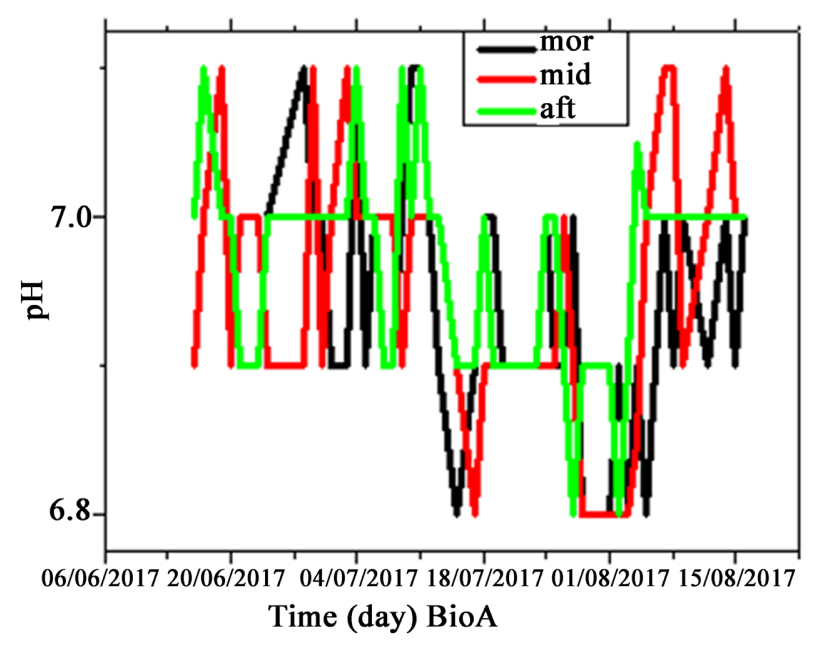

Figure 5. Variation of $\mathrm{pH}$ in digesters as a function of time.

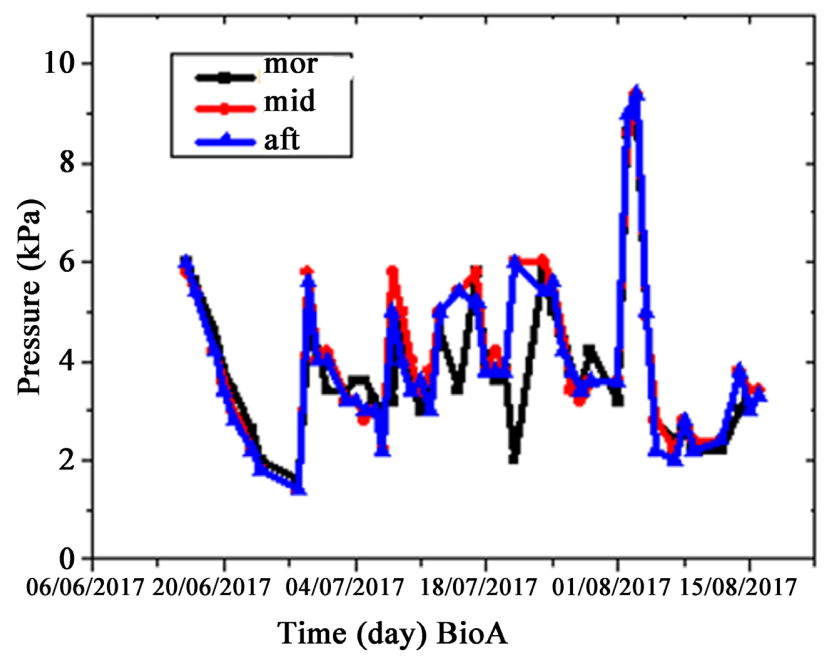

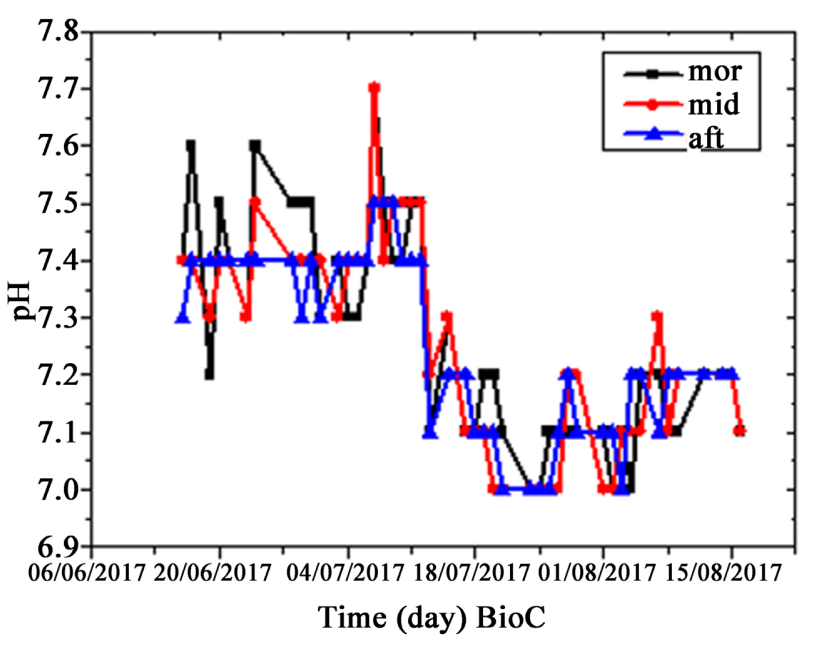

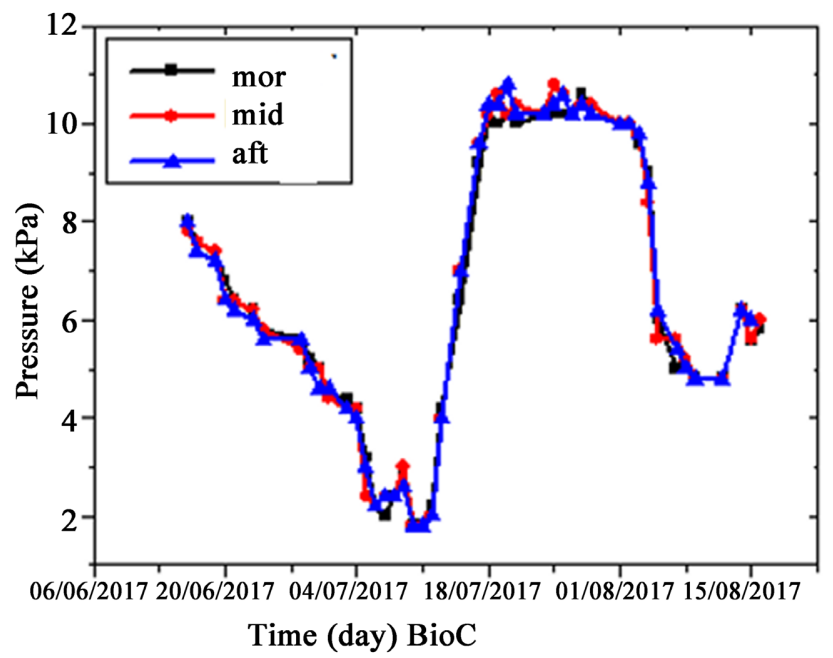

Figure 6. Evolution of the pressure of the biogas produced. 
has shown that the cashew apple as introduced into the BioA would have an inhibiting effect on the microbial activity of the environment and this would directly influence the production of biogas. In addition, the gas pressure is often depleted very quickly during ignition tests or when the gas outlet is connected to the gas analyzer. This is not the case for the pressure at the BioC, which can cook for several hours.

\subsection{Basic Composition of Biogas}

(Above version). After checking the pressure of the biogas, an analyzer is directly connected to the outlet of the valve which allows us to have the composition of the biogas in real time. In terms of composition, we were particularly interested in the concentration of $\mathrm{CH}_{4}$ and $\mathrm{CO}_{2}$ biogas. From the shape of these curves (Figure 7) we can visually see that these two digesters have different functions (in terms of productivity). This could be justified by the composition of the substrate but also by the fluctuations in temperature and $\mathrm{pH}$ of the environment. Indeed, as seen in the presentation section, these two digesters do not have the same substrate, which could explain these different behaviors. BioA's biogas has a percentage of $\mathrm{CH}_{4}$ which varies globally from $48 \%$ to $56 \%$ and $\mathrm{CO}_{2}$ which in turn varies from $41 \%$ to $49 \%$ depending on the hours of capture. As for the BioC, the percentage of $\mathrm{CH}_{4}$ varies between $53.36 \%$ and $57.13 \%$, and of $\mathrm{CO}_{2}$ which varies between $40.21 \%$ and $43.67 \%$, so the BioC gas is richer in methane, which would explain the fact that the cashew apple as introduced into the BioA would have an inhibiting power on the microbial activity of the environment. These proportions of $\mathrm{CH}_{4}$ compared to and those obtained by Kebe et al. in 2019 [11] ( $80 \%$ to $91 \%$ methane) with the fish residues from Get ndar in Saint-Louis, Senegal seem less efficient. On the other hand, it is important to note the absence of $\mathrm{CO}$ in our monitoring, a component of biogas that appears in the results of Kebe et al. with proportions ranging from 22 to $196 \mathrm{ppm}$. But compared to the results of Fall 2018 [3] (29\% to 47\% methane in the mesophilic regime), our results seem to be sufficiently efficient, but our results seem slightly lower than
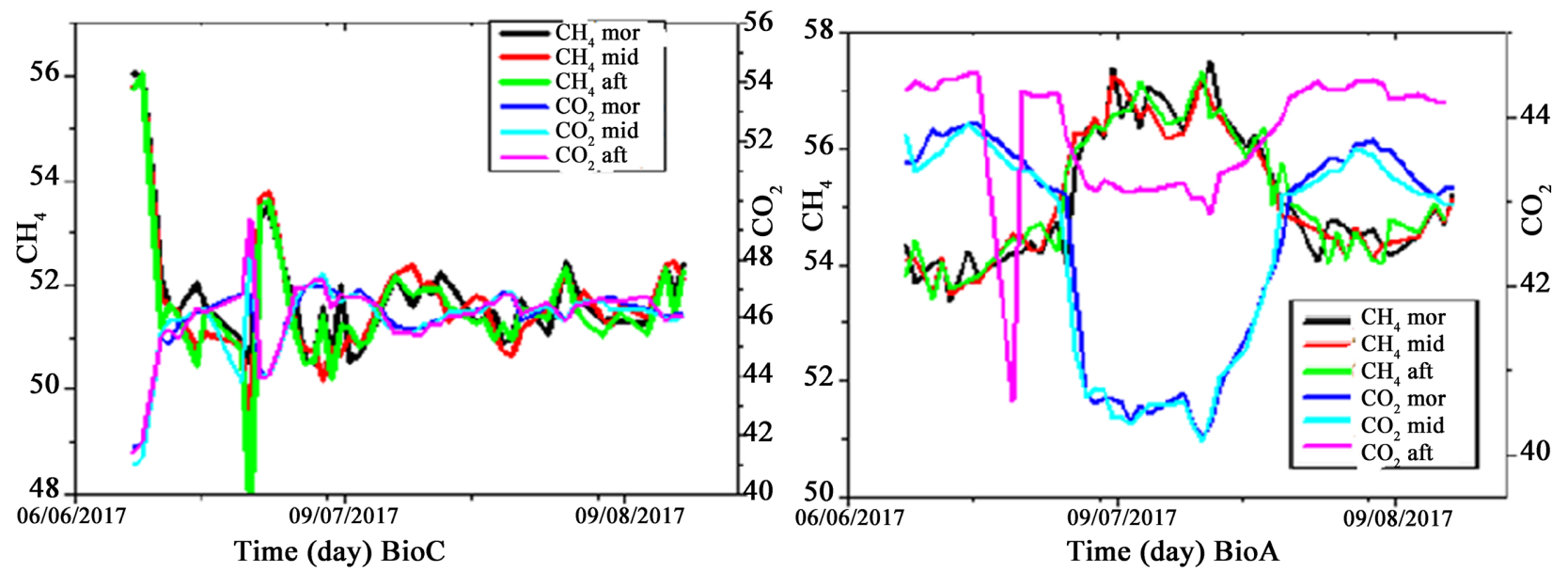

Figure 7. $\mathrm{CH}_{4}$ and $\mathrm{CO}_{2}$ content in biogas from the two digesters as a function of time. 
those obtained in the thermophilic regime $\left(45^{\circ} \mathrm{C}\right)$ with a percentage of $\mathrm{CH}_{4}$ ranging from $18 \%$ to $60 \%$.

Nevertheless, in terms of stability, the results obtained at the BioC level present a better stability compared to those obtained by Fall in 2018 [3]. Furthermore, the methane percentages obtained by Faye et al. 2020 [12]: cow dung 58.52\%, $50 \%$ cashew pulp and 50\% cow dung in co-digestion $61.30 \%$, cashew apple pulp $62.95 \%$ are quite satisfactory results and much more stable than those of Fall 2018. These results open a better perspective for the codigestion of méthanisables substrates in the biogas sector in Senegal.

Moreover, another phenomenon could also explain these different behaviors; at the BioA level, the digestate is very foamy compared to that of BioC (Figure 8). This is often created by the accumulation of $\mathrm{NH}_{3}$ and long-chain fatty acids [13]. Hence the decrease in biogas production at the BioA level.

But one of the components of biogas that most caught our eye is hydrogen sulphide $\left(\mathrm{H}_{2} \mathrm{~S}\right)$. In installations with a specific $\mathrm{H}_{2} \mathrm{~S}$ sensor, it often appears as

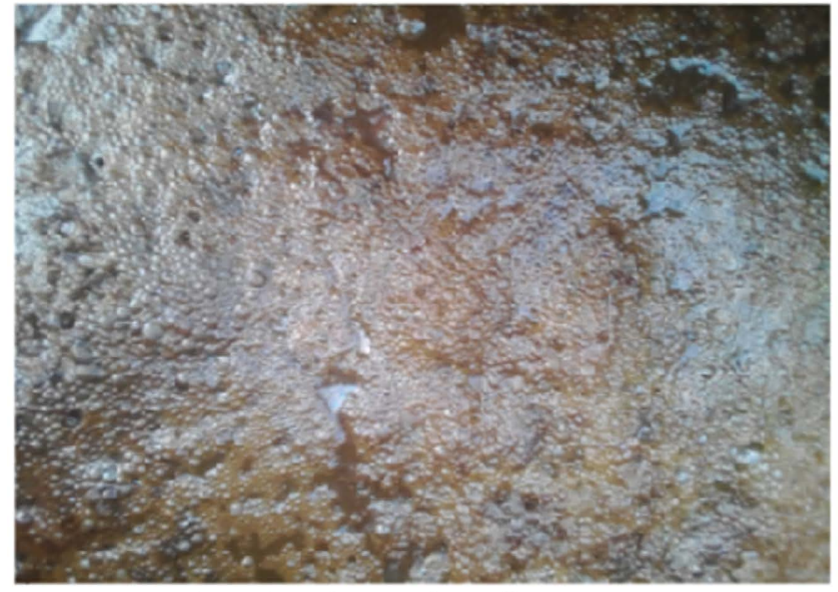

BioA foaming surface digestate

Figure 8. Appearance of the digestate of the two digesters.

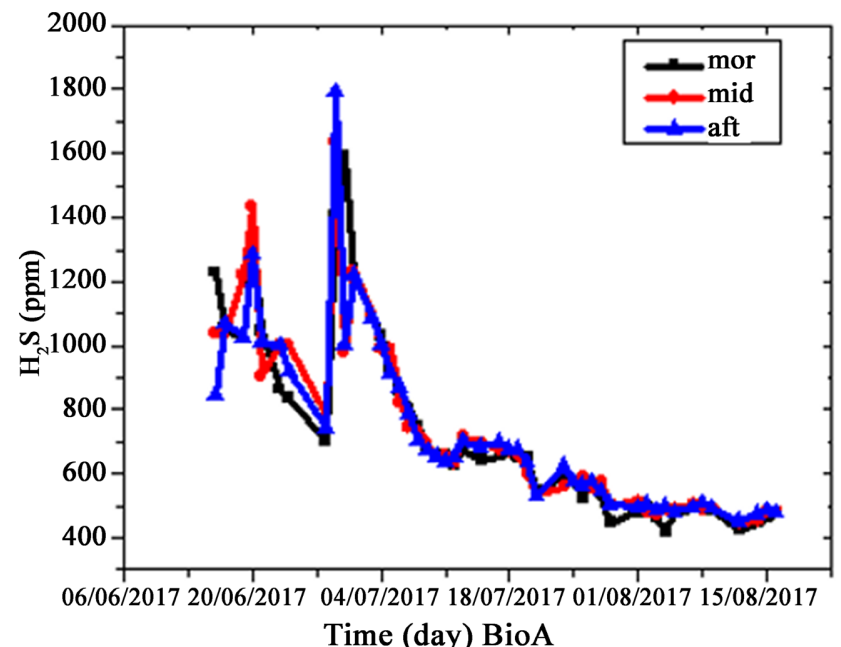

Figure 9. Variation of $\mathrm{H}_{2} \mathrm{~S}$ in the gas composition of the two digesters.

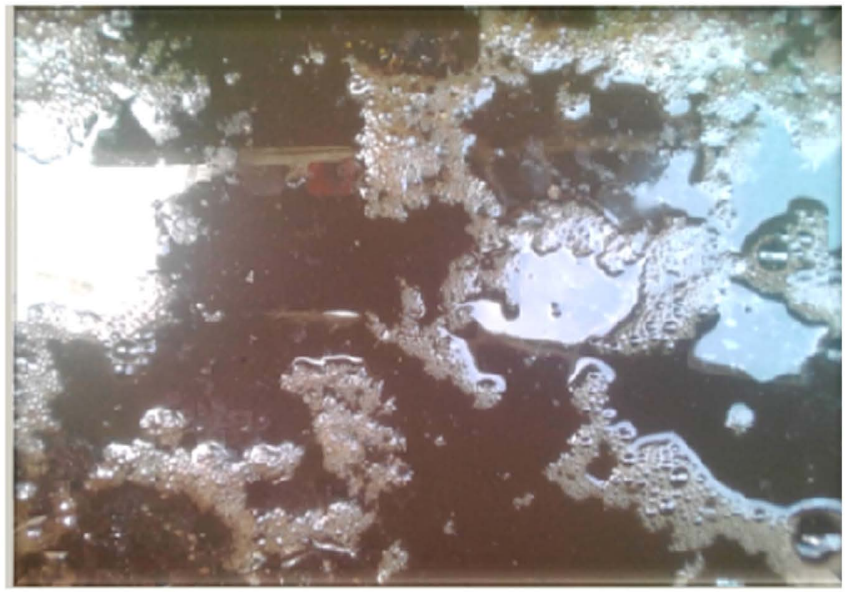

BioC low foaming surface digestate

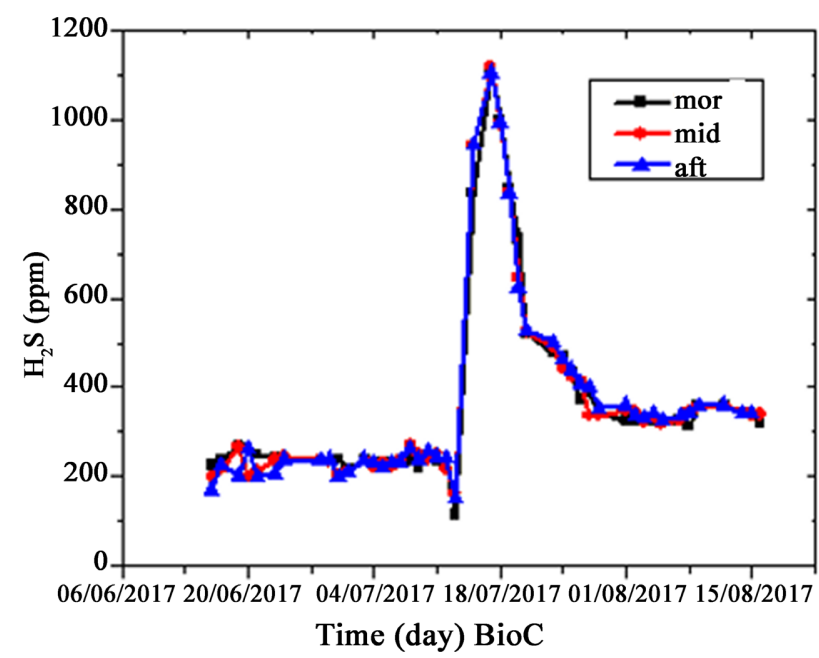


traces when the biogas obtained is analyzed. This is not the case for our two systems, which is why we have had $\mathrm{H}_{2} \mathrm{~S}$ proportions of up to $1800 \mathrm{ppm}$ in the BioA (Figure 9). However, $\mathrm{H}_{2} \mathrm{~S}$ is not only a corrosive gas, but it is also a gas that is highly dangerous for living organisms depending on the quantity inhaled [14] [15] [16] [17] and [18].

The results of this study have allowed us to understand the real discrepancy between studies carried out under optimum laboratory conditions and those carried out in situ from different angles. From the point of view of temperature and $\mathrm{pH}$, laboratory scale tests offer more stability.

Indeed, with command control systems, the temperature can be fixed at a well-defined value according to the chosen regime (mesophilic or thermophilic in most cases) as was the case in Fall, 2018 [3]. This allows for a more stable reaction medium with little variation in $\mathrm{pH}$ and more efficient microorganisms. This allows for higher yields in terms of percentage of $\mathrm{CH}_{4}$ in the biogas obtained and a shorter hydraulic retention time with increasing temperature.

This is not the case for in situ installations. Indeed, these systems are exposed to environmental conditions that fluctuate according to the season, day and time of day. Since these digesters of the PNB-SN type do not benefit from thermal regulation systems, the temperature of the reaction medium often varies according to the ambient temperature, which also affects the $\mathrm{pH}$ and therefore the bacterial consortium. Due to the instability of the parameters that determine the anaerobic digestion media, the yield of the digesters is reduced with a low percentage of biomethane and a higher percentage of $\mathrm{CO}_{2}$.

However, one of the parameters that most caught our attention was hydrogen sulphide with a concentration approaching $2000 \mathrm{ppm}$ due to the lack of adequate $\mathrm{H}_{2} \mathrm{~S}$ filters in our facilities. This constitutes a major risk for operators according to the Ontario Ministry of Labor's Occupational Health and Safety Guidelines for Agricultural Operations in Ontario, Section 7: "Hazardous Atmospheres and Confined Spaces" [16]; hence the notion of the technology transfer limit in the field of methanization in Senegal.

In spite of these constraints linked to the obsolescence of existing installations, the conversion of organic waste into biogas in Senegal is an emerging sector that could play an important role in the fight against greenhouse gas emissions. The development of this sector could enable decision-makers to settle once and for all the issue of non-conventional landfills by setting up a waste sorting system, the fermentable fraction of which will be sent to more modern anaerobic digestion plants for more sustainable cities.

\section{Conclusion}

The anaerobic digestion sector in Senegal is of particular interest to the scientific world because of the diversity of the substrates that can be mobilized. Méthanisables substrates such as cow dung, pressed cashew apple, fish residues, the fermentable fraction of household waste, slaughterhouse waste, sewage treatment plant sludge, 
etc. are available throughout the country. But most of the in-situ installations proposed by the PNB-SN seem to be clothed because they do not have a control system with a dimensioning to be desired. This makes studies difficult, hence the lack of viable data. As shown in the results, the studies carried out show instability of the parameters such as the temperature which varies a lot according to the ambient temperature and the period with values going from $29.1^{\circ} \mathrm{C}$ to $36.6^{\circ} \mathrm{C}$. In addition to the temperature, we note the presence of hydrogen sulfide (100 to $1900 \mathrm{ppm}$ ) which is not often eliminated in an effective way but also a good fraction of $\mathrm{CO}_{2}$ ( $40 \%$ to $\left.45 \%\right)$; which negatively influences the calorific value of the biogas obtained. It is also important to remember that most of the biodigesters installed by the PNB-SN are practically no longer working because of the lack of interest and lack of mastery of the technology observed among the beneficiaries. Moreover, studies on a laboratory scale seem to be non-existent and are carried out with the means at hand, hence the notion of the limit of technological transition. This explains the need to reform this sector with a political will of our leaders, as it exists almost everywhere in European countries for better energy recovery of waste.

\section{Conflicts of Interest}

The authors declare no conflicts of interest regarding the publication of this paper.

\section{References}

[1] Colin, H. (1993) Thies: L4abattoir fertilise au lieu de polluer. Spore 47. CTA. Wageningen, The Netherlands.

[2] Minister of Energy of Senegal (2021) ARRETE MINISTERIEL n ${ }^{\circ} 12100$ en date du 30 décembre 2009 portant création, organ-isation et fonctionnement du Programme National de Biogaz domestique du Sénégal (PNB-SN). http://www.jo.gouv.sn/spip.php?article7948,consultation

[3] Fall, M. (2018) Caracterisation physico-chimique et valorisation energetique des dechets solides pour la region de Dakar. Thèse de doctorat Universite Cheikh Anta Diop de Dakar.

[4] ONAS Rapport Final Biogz (2013) Etude d'etablissement d'une base de reference pour le projet biogas.

[5] Kim, M. and Speece, R.E. (2002) Comparative Process Stability and Efficiency of Anaerobic Digestion; Mesophilic vs. Thermophilic. Water Research, 36, 4369-4385. https://doi.org/10.1016/S0043-1354(02)00147-1

[6] Dana, R. (2010) Macro-Scale Biogas Production: A Beginners Guide. The National Sustainable Agriculture Information Service, ATTRA. https://attra.ncat.org/

[7] Labatut, R.A., Angenent, L.T. and Scott, N.R. (2014) Conventional Mesophilic vs. Thermophilic Anaerobic Digestion: A Trade-Off between Performance and Stability? Water Research, 53, 249-258. https://doi.org/10.1016/j.watres.2014.01.035

[8] Zennaki-Bensouda, Z., Zaid,,A., Lamini, H., Aubineau, M. and Boulil, M. (1996) Fermentation méthanique des déchets de bovins: étude du temps de retention hydraulique, de la temperature et de la concentration en substrat. Traopicultura, 14, 
134-140.

[9] Fulford, D. (1998) Running a Biogas Programme, a Hand Book. "How Biogas Works". Intermediate Technol Publication, London, pp. 33-34.

[10] Morau, D. (2006) Modélisation des dispositifs de revalorisation énergétique des déchets solides et liquides: séchage, méthanisation, incinération: mise en oeuvre d'un outil d'aide à la conception multisystèmes et multi-modèles. Mécanique [physics.med-ph]. Université de la Réunion, Français.

[11] Kebe, N.N., Fall, P.A., Ndiaye, D. and Diouf, D. (2019) Residues of the Transformation of Halieutics Products: An Alternative Substrate for Energy Valorization of Wastes by Methanisation for a Local Sustainable Development (Preliminary Results). African Journal of Environmental Science and Technology, 13, 291-295. https://doi.org/10.5897/AJEST2018.2549

[12] Faye, O.K., Ndiaye, L.G. and Sarr, B. (2020) étude comparative de la digestion anaérobie entre pulpes de la pomme de cajou, bouse de vache et leur codigestion. SOAPHYS, 2, C20A05-1 à C20A05-8. https://doi.org/10.46411/jpsoaphys.2020.01.05 www.soaphys.org/journal

[13] ADEME (2014) Guide complet à destination des exploitants d'unités méthanisation. ADEME Bourgogne, p5-12.

[14] American Society of Agricultural and Biological Engineers (2011) Manure Storage Safety, ASABE EP470 JAN1992 (R2005). American Society of Agricultural and Biological Engineers, Joseph.

[15] American Society of Agricultural and Biological Engineers (2010) Ventilating Manure Storages to Reduce Entry Risk, ANSI/ASABE S607 OCT2010 (R2019). American Society of Agricultural and Biological Engineers, Joseph.

[16] Ministère du Travail de l'Ontario (2009) Directives concernant la santé et la sécurité au travail à l'intention des opérations agricoles en Ontario, Section 7: Atmosphères dangereuses et espaces exigus.

[17] Ministère du Travail de l'Ontario (2011) Alerte I33: Dangers atmosphériques associés aux silos hermétiques dans les exploitations agricoles.

[18] Patni, N.K. and Clarke, S.P. (2003) Gaseous Emissions in Swine Barns and during Slurry Mixing in Sub-Floor Pits, ASAE Meeting Paper Number 034081. American Society of Agricultural and Biological Engineers, Joseph. 